their minds in kaleidoscopic fashion. Again and again emerge a developing work interest, a sense of emancipation, the mating instinct, the desire for success. The counselor seems to understand. Covering up the mechanical follow-up devices we have discussed, he helps Peter to face the fact of becoming twenty-one. He helps him to make progress in an occupation which suits his ability and which he will enjoy when he has grown up.

\title{
OCCUPATIONAL MATERIAL NEEDED BY THE TEACHERS AND USE TO BE MADE OF IT
}

\author{
Cleo Murtland \\ Professor of Education, University of Michigan
}

\begin{abstract}
A VARIETY of occupational material is needed for effective work in guidance, counseling, and placement, for two obvious reasons. There are many occupations in present-day life. A goodly number of occupations are of immediate interest to the pupils, and a still greater number are important as future possibilities. The second accepted fact is that young people vary widely, and individual differences must be expected to affect the extent and quality of the vocational information they acquire, and the wisdom with which they may be expected to choose the immediate and the future occupation.

Considerable occupational source material for the teachers' and for pupils' use, and material prepared especially for the pupils' use is required in every phase of the work. While the list given here may suggest little new material, it is necessary to have it at hand for this discussion.
\end{abstract}

\section{Types of Occupational Material}

Three types of material are essential: (1) printed matter, (2) illustrative material, and (3) outlines or plans for analyses. Indicated briefly these are as follows:
1. Printed matter.

A. Industrial studies:

(a) Descriptive for general information about specific industries or groups of allied industries.

(b) Organization plans showing schemes in use by various industries.

(c) Charts showing geographical distribution of industries.

B. Occupational studies:

(a) For teachers' use:

(1) In analytic form - preferably a standard form and complete in detail and treatment - and in manual form if possible.

(2) In descriptive form to round out lessons or supplement manual material.

(3) Job analyses for specific job activities and requirements.

(4) Legal restrictions or requirements of specific types of work - hours and conditions of labor, workmen's compensation, minimum wage.

(b) For pupils' use:

(1) Pamphlets setting forth local occupations in brief popular statement with illustrations or cartoons. 
(2) Charts depicting and explaining local occupations.

(3) Promotional charts in simplified form.

C. Books:

(a) For teachers' use:

(1) Standard technical reference books and manuals.

(2) Descriptive and historical material.

(3) Standard reference and textbooks on economics of industries and occupations.

(b) For pupils' use:

(1) Textbooks on occupations.

(2) Social science texts.

(3) Elementary economics texts.

D. Magazines and newspapers for current material:

(a) A file of clippings and pictures for phases of occupational study.

(b) Industrial and trade catalogues.

2. Illustrative and demonstration material.

A. Product material:

(a) Raw materials in stages of production:

(1) Collected and made by teachers and pupils.

(2) Commercial exhibits, as silk, flax, and sugar.

(b) Exhibits of finished products:

(1) For a single industry.

(2) For a group of industries.

(c) Markets for goods produced and distribution.

(1) Local products.

(2) Key or essential products as meat, iron, etc.

(d) Slides showing products and processes.

B. Occupational material:

(a) Models for demonstration.

(b) Pictures and charts depicting occupations. (c) Demonstration of mechanies of an occupation, as telephone service.

(d) Moving pictures of industries and industrial processes. (Slow movement type of special operations.)

3. Outlines or plans for occupational analyses:

A. For teachers' analyses of,

(a) industries.

(b) groups of occupations.

(c) jobs or operations.

B. For pupils' studies:

(a) Groups (and "fields") of occupations.

(b) Specific occupations or jobs.

This appears to be a formidable list, and much of it too bulky or too variable and changing to be practicable. Exhibits and charts must be stored and printed material classified, and arranged in available form. This requires space and time as well, since some person must be responsible for it. If vocational information is to be given effectively and counseling is to be done satisfactorily, these materials must be available for the teachers' use, and kept up to date systematically.

An occupations laboratory under the control of a counselor who directs pupils and teachers in the use of these materials is most desirable. The next best plan is to have the material in the school library classified and made accessible as occupational material. Exhibits and other bulky illustrative material, by this plan, would be placed in the school museum or storeroom. When schools lack both, or one or the other, teachers must gather and take care of their own material - a plan that is wasteful since it is likely to mean much duplication of work and loss of materials. The plan that is adopted by 
any locality should in any case include careful classification of material, so as to make it available for instruction in the choice of an occupation for varying types of pupils, for placement purposes, and for occupational instruction in all grades.

\section{Occupational Material as} SUBJECT MATTERR

Occupational material has definite, but varied uses, which are governed by factors that too often are merged or confused. It is pertinent here to consider the use of occupational material from the standpoint of subject matter, and from the standpoint of the use pupils will make of it.

The forms of occupational material indicated here are used for the three phases of vocational guidance: (1) as vocational or occupational information, (2) as material to aid in the choice of an occupation, and (3) as a basis for placement. Indicated briefly these are:

1. As vocational or occupational information:

A. About occupations:

(a) Descriptions.

(b) Analyses.

B. About occupational opportunities:

(a) For given abilities and qualifications.

(b) Immediate employment.

(c) Future vocation.

C. About occupational requirements:

(a) Entrance:

(1) Knowledge.

(2) Skills.

(3) Physical and Personal fitness.

(b) "Sticking" requirements.

(c) Promotional requirements.
2. As material to aid in the choice of an occupation:

A. For the immediate job:

(a) Entrance requirements:

(1) Knowledge.

(2) Skills.

(3) Physical and Personal fitness.

(b) Wages.

(c) Responsibilities.

(d) Opportunities, the way out, and the next step.

B. For the future job, trade, or business.

(a) Entrance requirements:

(1) Education.

(2) Skills.

(3) Physical and personal fitness.

(b) "Sticking" requirements:

(1) Standards of work.

(2) Responsibility - capacity for.

(3) Personal qualifications:

(a) Manner.

(b) Readiness.

(c) Reserve.

(d) Dependability in routine and emergencies.

(c) Promotion or advancement opportunities.

3. As a basis for placement:

A. For the immediate job.

B. For after school and summer jobs.

C. For the steady job.

D. For future job - so-called "life work."

\section{Use of Occupational Material and Pupils' NeEds}

These applications of occupational materials are needed in every situation. It is obvious, however, that not all occupational material may be used with any one group, or individual, and the same method will not apply equally 
well in all instances. What is used and the way it is used should be determined by the pupils' interests and abilities, their occupational potentialities, and their immediate and future needs.

For example, there are pupils of elementary school attainment who are normal but of working age who will go to work as soon as the law releases them; there are others of elementary grade retarded and of working age. In the secondary schools, including the vocational schools, there are normal work-age pupils, and retarded or failed pupils of working age. There are in both the elementary and the secondary schools young people with a school attendance expectancy covering the elementary and secondary school periods, perhaps with higher educational expectancy, who require a different type of occupational study from that needed by the go-to-work type of pupil.

The use to be made of occupational material differs as groups and individuals differ. These differences affect, (1) the approach or approaches to occupational study, (2) the character and amount of subject matter to be used with pupils in given situations, and (3) the kind and nature of experience that should be provided.

The method of approach to occupational study is affected, not only by the abilities and interests of the pupils, but by their occupational potentialities and their school attendance expectancy. Furthermore the occupations they may enter necessarily affect instruction. Certainly the featuring of professions with college degree requirements with pupils for whom employment is on the horizon either as release from school or as a means of learning a trade not taught in the schools, is misdirected effort, and, perhaps, a doubtful policy. It is as much the responsibility of the school to make a good case for trade and mechanical occupations and for business, as it is for the professions.

Taken from the standpoint of employment there are conditioning factors to be reckoned with in attempting occupational instruction with

1. The immediate-job pupil:

A. Who aids the family - after school, Saturday, and holiday employment.

B. Who wishes to stay in school and will work for the privilege in after-school odd jobs, Saturday work.

C. Who wants to be released from school and probably is not interested in any particular kind of a job. Probably retarded.

2. The near-future job pupil:

A. Who will take any job - for release from school at close of compulsory attendance period.

B. Who aspires to a trade or business occupation. - Something to learn and promotion in view.

3. The future-job pupil:

A. Of relatively long school expectancy.

Character and amount of occupational information also varies for the different types of occupations and pupils' interests and outlook.

A. The immediate job without a future for which there should be provided:

(a) Specific detailed information about the character of the work.

(b) Skills required for the job.

(c) Rules and regulations, if any.

(d) General code - where rules are lacking.

(e) Plant or firm policy or policies, especially those that affect young workers. 
(f) Hazards, if any, and workers' rights and obligations where hazards exist.

(g) Inspiration for the work to be done.

(h) Development of self-confidence and self-reliance, if needed.

(i) Wages - method of payment, hours, overtime.

B. The immediate job with a future for which there should be provided:

(a) Specific information about the job.

(b) General knowledge required, and that specifically related to the job.

(c) Nature and extent of skills required.

(d) Rules and regulations governing the establishment, department, and job.

(e) Plant or firm policy or policies affecting workers.

(f) Code of the occupations, as for electrical work.

(g) Hazards of the occupation legal rights and responsibilities of the worker and employer where hazards exist.

(h) Wages - method of payment - rate for overtime.

(i) Bonus or premium system, if any.

(j) Employees' benefit, if any.

(k) Hours - regularity of work, overtime.

(l) Promotional opportunities and order of promotion - relation of one job to others, especially for group or team workers.

(m) Provision for information about the next job ahead.

C. The future job with a future for which these should be provided.

(a) Information about occupations in comparative form. (b) Brief history and descriptions of fields of work and specific occupations for background.

(c) Educational requirements of a number of occupations.

(d) Skills and special knowledge required in various fields and occupations.

(e) Codes or regulations and principles underlying them.

(f) Standards of workmanship required.

(g) Wages in various occupations, and wage systems used.

(h) Survey of an industry made by the pupils.

(i) Occupational analyses made by the pupils.

(j) Promotional charts made by the pupils.

(k) Types of industrial organizations charted by the pupils.

(l) Demonstrations and tests.

The kinds and nature of experience that may be provided, if the term experience may be used broadly, is also somewhat varied. Broadly, (1) observation, (2) try-out courses, and (3) actual participation furnish what one may justly call getting the feeling of the work in hand. Since experience and outlook are important factors in selecting and preparing for occupations, doing should be provided for wherever possible. This may be done through

A. Observation:

(a) Demonstrations of occupational activities, skills, etc.

(b) Visits to places of employment with written reports or oral descriptions to organize and clarify knowledge gained.

B. Try-out courses in

(a) Shop courses giving variety of experiences to demonstrate technique and content. 
(b) Commercial courses on similar basis.

C. Participation in

(a) Productive school shops as direct preparation for employment.

(b) Industrial establishments as employed workers or as pupils on the coöperative plan.

For the-go-to-work type of pupil the occupation without a future, little description of the occupation is practicable. Since promotion is improbable, other gains to be made in working experience, such as taking and executing directions promptly and satisfactorily, readiness to measure up to requirements, steadiness, attention to business, and like matters should be capitalized by the counselor and placement officer.

For the go-to-work type of pupils, the immediate job with a future presents a very different problem. Educational requirements, though of less than high school grade, or at most not more than high school grade, promotional possibilities and probabilities, skills required, special training needed, furnish much material for the teacher and counselor. The pupil interested in future probabilities approaches employment and occupational opportunities with an expectant attitude and an interest that may readily be capitalized. Furthermore, in observing people at work and in try-out courses where they are provided, he gets a type of experience which for him is a fairly good substitute for the actual participation that is needed by the pupil who will take any job.

The future job of young people who remain in school for a prolonged period presents very different instructional problems. Informational courses may be amplified, observation of occupa- tional life provided for, and a number of types of occupational activities courses may be used to give experience. Investigation of industries and employments, preparation of charts, studies of occupations and occupational requirements may be done by the pupils as projects. Emphasis should be placed upon getting first-hand information for the experience values it furnishes. Getting the feeling of a type of work is a very important consideration in guidance and counseling. Without it, explanations, directions, and descriptions are likely to be mere words.

\section{Study of Occupations a Continuous Process}

Occupational study must "carry on" if teachers are to give occupational instruction satisfactorily. Changes in industrial life occur. New machines are adopted, reorganization of departments and plants are frequent, realignments of work and changes in administration policy make important changes, and legislation sometimes effects changes. If an occupational laboratory or vocational information department in the school library is available, counselors and teachers will be induced to go for source material frequently. If this material is up-to-date, with catalogues, clippings, and advertisements available, teachers will be directed to new material, if it is not actually at hand. Once an inquiring attitude toward occupational material is developed, the teacher will find many sources to draw upon.

Analysis and interpretation of occupational material, which includes the setting up of information about an industry and occupation, or a group of occupations, with something of the historical development and its importance at the present time, requires a technique that cannot be picked up by random effort. Workers in this field cannot 
learn how to use occupational subject matter, or teach pupils how to use and understand the significance of occupational activities by reading alone. Experience in collecting and organizing information, and in going through the grind of making job analyses with first hand observation, or if possible by actual experience, is an essential factor in preparation for occupational instruction.

The teacher needs to do this kind of study and investigation even though satisfactory printed and illustrative material for pupil's use is available and abundant. Considerable attention needs to be given to this for teachers tend to use pupils' material, not only as a means of approach, but they are inclined to limit their own point of view to pamphlet material which has been purposely limited to the pupil's outlook and ability.

A few people train themselves for this varied and complicated work, but with occupational instruction now so generally accepted, organized training is essential if instruction, counseling, and placement are to keep faith with people of varying potentialities, and aid in bringing about better employment conditions for young people.

\title{
PHYSICAL EXAMINATIONS AS AN ELEMENT IN VOCATIONAL GUIDANCE AND TRAINING
}

\author{
Jacob A. Goldberg, A.M., Рh.D. \\ Director, Committee for Health Service among Jews, New York City
}

IN a recent discussion of the health conditions among the students of a certain trade school, the question was raised as to whether or not a preliminary physical examination was made of the applicants for admission, in order to determine their physical fitness to follow out their initial choice of an industrial career and to undergo training. The reply to the question by the superintendent of this particular school was: "I have been in this business so many years that I can tell the fitness of an applicant by just looking at him." Such "powers of divination" have been assumed by other vocational counselors, though the tendency, fortunately, has been in the direction of reliance upon more exact methods, including psychological tests, occasionally coupled with thorough physical examinations.

To the students of the vocational guidance movement, it is quite apparent that a mere hasty look at an appli- cant for vocational guidance or a few minutes' talk with him, does not and cannot in itself furnish sufficient information upon which to base an accurate appraisal of the vocational aptitude and ability of the complex human being under consideration. Nor does the psychological test, coupled with such interview, supply more accurate and a much greater amount of information upon which to base a reliable and definite opinion. In order that any scheme of vocational guidance, and thence vocational training, may contribute to an intelligent choice of vocation, it is essential that the applicants be considered physically, mentally, and temperamentally. Experience with modern types of vocational training has fixed as a basic element to such a plan careful selection of pupils for the vocational courses so as not to admit the physically or otherwise unfit. 